\title{
PARTICIPAÇÃO DE IDOSOS EM FÓRUNS DE CIDADANIA - SÃO PAULO, SP
}

\author{
PARTICIPATION OF ELDERLY IN CITIZENSHIP FORUMS - SÃO PAULO, SP
}

\author{
Áurea Eleotério Soares Barroso ${ }^{1}$ \\ Maria Cecilia Teodoro Sanches ${ }^{2}$
}

RESUMO: A pesquisa buscou compreender como Fóruns de Cidadania localizados no Município de São Paulo, SP vêm se constituindo como um sujeito coletivo, na direção da conquista e efetivação de direitos de cidadania. Foi utilizado o método qualitativo, compreendendo a coleta de depoimentos, levantamento documental e pesquisa bibliográfica. $\mathrm{O}$ marco teórico teve como base os seguintes autores: Beauvoir (1990); Freire (2005); Neri (2007); Gohn (2013); Faleiros (2014), entre outros. Trata-se de estudo longitudinal, as autoras orientam-se por suas vivências, enquanto educadoras em gerontologia nesses espaços. $\mathrm{O}$ estudo revelou que as principais discussões e lutas empreendidas nesses espaços estão voltadas para ampliação do acesso e melhoria nos atendimentos de saúde, lazer, esporte, transporte público entre outros. A criação de redes nos territórios constituídas por Conselheiros de direitos dos idosos, pesquisadores, profissionais, agentes do poder público entre outros tem contribuído para colocar questões vivenciadas no cotidiano pelos idosos na agenda da cidade de SP. Uma conquista alcançada nesse processo diz respeito à ampliação do diálogo entre o Estado e os representantes da população idosa.

Palavras-chave: Idosos. Participação social. Direitos.

ABSTRACT: The research sought to understand how the Citizenship Forums located in the city of São Paulo, SP, have become a collective subject, in the direction of the conquest and realization of citizenship rights. The qualitative method was used, comprising the collection of statements, documentary survey and bibliographic research. The theoretical framework was based on the following authors: Beauvoir (1990); Freire (2005); NERI (2007); Gohn (2013); Faleiros (2014), among others. This is a longitudinal study, the authors are guided by their experiences, as educators in gerontology in these spaces. The study revealed that the main discussions and struggles undertaken in these spaces are aimed at expanding access and improving health care, leisure, sports, public transportation, among others. The creation of networks in the territories constituted by Elderly Rights Counselors, researchers, professionals, agents of public power among others has contributed to put the theme of aging on the agenda of the city of São Paulo and ensure citizenship rights. An achievement achieved in this process concerns the expansion of dialogue between the State and the representatives of the elderly population.

Keywords: Elderly. Social participation. Rights.

\footnotetext{
I Pós-Doutora em Ensino, Pesquisadora da Pontifícia Universidade Católica de São Paulo com foco na participação social de idosos em espaços coletivos. https://orcid.org/oooo-ooor-6I8o-6209. E-mail: barrosoaurea@gmail.com

${ }^{2}$ Assessoria Técnica em Fóruns de Cidadania da região leste de São Paulo e Interfórum desde i996. Assistente Social, Especialista em Gerontologia,. https://orcid.org/oooo-ooo2-2316-2876. E-mail: cicateodoro@uol.com.br
} 


\section{INTRODUÇÃO}

Estamos vivendo um momento singular na história, pela primeira vez, a maioria das pessoas pode esperar viver até os 60 anos ou mais de idade (OMS, 2015). No mundo, a cada segundo, duas pessoas celebram seu sexagésimo aniversário. Uma em cada nove pessoas tem 6o anos ou mais e estima-se um crescimento para uma, em cada cinco, por volta de 2050 (UNFPA, 2012). Ainda segundo a ONU, em 1950, havia 205 milhões de pessoas idosas no mundo. Em 2050 projeta-se que cheguem a dois bilhões de pessoas.

O envelhecimento populacional está em curso em todos os países em ritmos diferentes, em razão das condições de vida da população de cada localidade.

O número de pessoas idosas tem aumentado significativamente nas últimas décadas no Brasil. De acordo com o Instituto Brasileiro de Geografia e Estatística (IBGE, 2018), a população manteve a tendência de envelhecimento dos últimos anos e ganhou 4,8 milhões de idosos, desde 2012, superando a marca dos 30,2 milhões, em 2017.

Segundo Pesquisa Nacional por Amostra de Domicílios (Pnad) do Instituto Brasileiro de Geografia e Estatística (IBGE), do total de 210,I milhões de habitantes do país, 34 milhões de brasileiros eram idosos, no quarto trimestre de 2019. (DIESE, 2020)

Estudos mostram que a humanidade sempre sonhou viver mais. Assim foram feitos investimentos em diversas áreas para alcançar esse objetivo, como mencionaremos a seguir. Ampliou-se o atendimento às gestantes no período pré-natal e durante o parto e à criança.

Um marco para a saúde pública foi o uso em grande escala de antibióticos em seres humanos, a partir da década de 1940 assegurando uma sobrevida para grande parcela da população que morria em decorrência de doenças infecciosas.

Merece lembrar que a migração da população rural para as cidades em razão de políticas de industrialização principalmente entre 1950 e 1980 facilitou a aplicação de técnicas médico-sanitárias, como o combate de agentes transmissores de doenças, ações de higienização e campanhas de vacinação com maior alcance. Somado a isso, uma maior parcela da população passou a ter acesso a serviços de saneamento básico, iluminação e coleta de lixo. Ampliou-se também a rede de serviços assistenciais e de educação.

As medidas mencionadas anteriormente, além de outras, resultaram em uma queda significativa da mortalidade, notadamente infantil, e em um aumento da expectativa 
de vida ao nascer, ou seja, contribuíram para o prolongamento da vida humana. Mas essa conquista é recente para os(as) brasileiros (as), em 1960 um recém-nascido poderia esperar viver até 48 anos. O aumento da expectativa de vida ao nascer do(a) brasileiro(a) aumentou 6,9 anos nas últimas duas décadas. Em 2020 era de 76,7 anos e em 2050 aumentará para 81,29 anos," igualando-se à de países com elevado Índice de Desenvolvimento Humano (IDH), como Islândia (8I,8 anos) e Japão (82,6 anos)”. (DÓREA, 202I, p.30)

Paralelamente ao envelhecimento populacional, ocorreram mudanças no padrão de adoecimento. As doenças passaram de um processo infeccioso agudo, que levava à cura ou então à morte, para um estado crônico que acompanha as pessoas durante muitos anos. Nesse contexto, as doenças crônicas não transmissíveis, entre elas as cardiovasculares, o câncer e a depressão, são cada vez mais importantes como causas de invalidez e morte.

Como mencionamos, as doenças infecciosas diminuíram $e$ as doenças crônicas passaram a ser preponderantes nas últimas décadas. Isso significa dizer que mais pessoas ficam doentes e menos pessoas morrem. Vale lembrar que, em algumas regiões do Brasil, encontramos a superposição de problemas de saúde pública, como a desnutrição, que implicam em maior risco de doenças infecciosas, além das doenças crônicas.

A multimorbidade, ou seja, a coexistência de duas ou mais doenças crônicas num mesmo indivíduo tem sido descrita como a condição crônica mais comum entre idosos: "Embora possa acontecer em qualquer faixa etária, sua presença entre idosos é mais a regra que exceção e sua frequência aumenta progressivamente com a idade, chegando a afetar cerca de 65\% dos indivíduos após os 65 anos”. (PEREIRA; ROSA, 2018, p. 96).

Entretanto, as referidas autoras salientam que, Embora a grande maioria dos idosos seja portadora de pelo menos uma doença crônica, nem todos ficam limitados e muitos levam uma vida perfeitamente normal, com suas enfermidades controladas e expressa satisfação na vida. [...] Assim, o conceito de saúde do idoso não se deve confundir com a presença de doenças ou idade avançada com ausência de saúde, que deve ser definida como uma medida da capacidade individual de realização de aspirações e da satisfação das necessidades, independentemente da idade ou da presença de doenças. (PEREIRA; ROSA, 20I8, p. 26)

Envelhecer sem a presença de doença é exceção e não regra. Por exemplo, quase todos os idosos têm perdas sensoriais limitantes na idade avançada, particularmente 
em termos visuais e auditivos. Certamente, há doenças com potencial mais incapacitante que outras, mas, desde que essas enfermidades sejam controladas, a pessoa pode almejar um envelhecimento saudável $\mathrm{e}$ isso passa pela preservação das capacidades físicas e mentais. (RAMOS, 2009)

As reflexões de Pereira e Rosa(2018), Ramos (2009) mencionadas anteriormente são fundantes no momento atual, quando o debate “velhice não é doença” alcança a agenda nacional e internacional. Essa discussão começou com a revelação do atestado de óbito do marido da Rainha Elizabeth II divulgado pelo jornal Daily Telegraph informando que ele faleceu de "velhice". O atestado foi assinado pelo médico da família real, Sir Huw Thomas.

A possibilidade de inclusão do código $\mathrm{MG}_{2} \mathrm{~A}$ - velhice, no capítulo 2I, da Classificação Internacional de Doenças - CID-II mobilizou pesquisadores, profissionais que trabalham com idosos e Associações ligadas ao envelhecimento como SBGG (Sociedade Brasileira Geriatria e Gerontologia) e Associação Brasileira de Gerontologia (ABG) que argumentam que o código $\mathrm{MG}_{2} \mathrm{~A}$ poderia omitir problemas de saúde que acometem a população idosa interferindo na coleta de dados epidemiológicos. A mobilização social teve êxito, a Organização Mundial da Saúde (OMS) recuou na sua decisão e ao invés de velhice ser caracterizada como doença constará “ declínio da capacidade intrínseca associado ao envelhecimento".

O documento existe desde 1900 e desde 2015 está sendo elaborada uma nova edição na qual entrará o código $\mathrm{MG}_{2} \mathrm{~A}$ que se refere à velhice, a partir de janeiro de 2022 .

A CID é uma importante ferramenta epidemiológica, classifica as doenças, os problemas relacionados à saúde e outras condições que possam demandar a utilização de recursos e serviços de saúde. Por meio desta padronização é possível desvendar e analisar a situação de saúde global em termos de doenças, sintomas, sinais, queixas, aspectos anormais, causas externas e aspectos sociais relacionadas à saúde contribuindo para adequação de serviços, definição e planejamento de investimentos e de políticas públicas.

O fato é que, não existe um idoso "típico". A diversidade das capacidades e necessidades de saúde das pessoas idosas não é aleatória, e sim advinda de eventos que ocorrem ao longo de todo o curso da vida e frequentemente são modificáveis. Há 
evidências científicas de que as pessoas idosas estão resignificando a velhice, muitas estão planejando estudar mais, alcançar algum sonho, desejo negligenciado. (OMS, 2015)

E, concordamos com Tótora (2008) quando diz que a realidade do envelhecimento, fenômeno histórico das sociedades atuais, impõe uma agenda que ultrapassa as dimensões biológicas, ou cronológicas, colocando desafios que atingem os aspectos sociais, políticos e, fundamentalmente, culturais. Estes últimos dizem respeito às mudanças nos valores instituídos. Trata-se, pois, da criação de novos valores, em que o envelhecimento constitua a potência imanente à vida.

A década de 1990 e início dos anos 2000 trouxeram avanços no campo dos direitos da pessoa idosa, a partir da promulgação da Constituição Federal da República de 1988. A Lei 8.842/1994 regulamentada pelo Decreto I.948/1996 (Política Nacional do Idoso), a Portaria 2.528/2006 aprovou a Política Nacional de Saúde da Pessoa Idosa e o Estatuto do Idoso instituído em Io de outubro de 2003 através da Lei $\mathrm{n}^{\mathrm{o}}$ 10.74I e foram aprovadas outras legislações específicas na dimensão nacional, dos estados e municípios para os idosos.

Faleiros (2014) ressalta a importância da instituição do ordenamento jurídico para população idosa. “ Foi na Constituição de 1988 que a velhice foi reconhecida não só no âmbito da seguridade social (Artigos 193 a 203) enquanto previdência, saúde e assistência, mas como protagonista na sociedade. É importante ressaltar que a seguridade social pressupõe a participação da população (FALEIROS, 2014, p.7)

No decorrer das últimas décadas, governos no âmbito federal, dos estados e municípios têm desenvolvido programas voltados para população idosa; porém, essas iniciativas ainda não se constituíram em uma política pública com cobertura e abrangência para atender as demandas deste grupo etário. (ROSA; BARROSO; LOUVISON, 2013).

Concordamos com Vieira (1992) quando afirma que a efetivação de direitos fundamentais requer participação social pois, "Não tem havido política social desligada dos reclamos populares. Em geral, o Estado acaba assumindo alguns destes reclamos, ao longo de sua existência histórica" (VIEIRA, I992, p. 232).

Diante desse cenário, os idosos vêm se inserindo em espaços coletivos de participação social conhecidos por Fóruns de Cidadania no Município de São Paulo 
em defesa de direitos fundamentais previstos em leis. Vejamos como Dallari (2004) referese aos direitos fundamentais: "Eles são ditos fundamentais porque é necessário reconhecêlos, protegê-los e promovê-los quando se pretende preservar a dignidade humana e oferecer possibilidades de desenvolvimento. Eles equivalem às necessidades humanas fundamentais". (DALLARI, 2004, p. 25)

A seguir definição sobre Fórum de Cidadania elaborada coletivamente pelos seus participantes.

É um espaço coletivo onde os idosos trocam ideias, experiências, informações, elaboram propostas e discutem sua cidadania. É um local privilegiado para discussão das políticas públicas, tais como: saúde, moradia, educação, lazer, cultura, entre outras (...) Os participantes do Fórum são idosos, grupos, entidades, profissionais dos setores da administração municipal, faculdades de terceira idade, movimentos sociais e populares.

O primeiro Fórum de Cidadania foi criado em 1995, por iniciativa de profissionais da Assistência Social com apoio de algumas pessoas idosas, com o passar dos anos foram abertos espaços coletivos desta natureza nas regiões sul, norte, leste, oeste e sul do Município de São Paulo. Durante o período pandêmico por covid-ı́ que o Brasil e o mundo estão atravessando, vinte e cinco Fóruns continuaram realizando encontros mensais virtualmente. Profissionais compartilhavam informações sobre cuidados e orientações sobre serviços públicos disponíveis neste momento.

Merece pontuar o acelerado envelhecimento populacional de São Paulo, capital do estado de São Paulo, onde estão localizados os Fóruns de Cidadania. O número de pessoas idosas representava 6,33\% em 1980 e subiu para $15,2 \%$ em 2019 - quase o triplo (CARLETTO,2020). Quanto as condições de vida, a diferença entre as regiões na expectativa de vida ao nascer chega a I4 anos na cidade de São Paulo. Os dados mostram que os idosos vivem realidades distintas nesta cidade. (PREFEITURA DO MUNICÍPIO DE SÃO PAULO, 2020).

Os Fóruns de Cidadania funcionam no formato de assembleia presidida por um idoso. Há sempre presença de profissionais da Assistência Social, psicólogos, de outras áreas do conhecimento e de funcionários da Administração Pública Municipal que compareçam com o propósito de prestarem esclarecimentos e embasarem teoricamente as discussões. A pauta gira em torno das demandas trazidas pelos idosos, como denúncia de 
maus tratos no transporte público, dificuldade de atendimento em serviços de saúde, entre outras. No final da reunião são feitos encaminhamentos às instâncias competentes para que sejam tomadas providências.

Os Fóruns de Cidadania não têm sede própria e, por esta razão, realizam reuniões mensais em espaços cedidos pela Prefeitura do Município de São Paulo, universidades, entre outros.

O presente estudo buscou compreender como Fóruns de Cidadania vêm se constituindo como um sujeito coletivo, na direção da conquista e efetivação de direitos para população idosa residente na cidade de São Paulo.

Foi utilizado o método qualitativo, compreendendo a coleta de depoimentos, o levantamento documental e pesquisa bibliográfica. Trata-se de estudo longitudinal, a pesquisa realiza observa observação participação no universo da pesquisa desde $2005 .{ }^{\mathrm{i}}$

As principais discussões e lutas empreendidas nos Fóruns de Cidadania estão voltadas para ampliação e melhoria dos serviços de saúde, transporte, moradia entre outros.

\section{METODOLOGIA}

No primeiro momento da pesquisa foi realizado o levantamento bibliográfico de livros, revistas científicas, dissertações de mestrado, teses de doutorado publicadas no Brasil. Estudo de legislações, dados e relatórios elaborados por institutos de pesquisa sobre o segmento de idosos. E leituras nos documentos nos acervos dos Fóruns (atas, folhetos de divulgação de suas atividades etc.).

Foi utilizado o método qualitativo, compreendendo a coleta de depoimentos obtidos por meio de questionários. Segundo Martinelli (2012), no que se refere às pesquisas qualitativas, exige-se do pesquisador uma contínua disponibilidade e real interesse em vivenciar a pesquisa. Concordamos com a autora e, por essa razão, para melhor apreensão da realidade em que o processo investigativo foi desenvolvido, nos apoiamos em estudos sobre a temática abordada e também nos saberes de profissionais que trabalham com população idosa em espaços governamentais e não governamentais na cidade de São Paulo.

As pesquisadoras são educadoras gerontológicas em Fóruns de Cidadania no Município de São Paulo, portanto, vivenciam " atitude participante", caracterizada "por 
uma partilha completa, duradoura e intensiva da vida e da atividade dos participantes, identificando-se com eles, como igual entre pares, vivenciando todos os aspectos possíveis da sua vida, das suas ações e dos seus significados" (CHIZZOTTI, 2003, p. 90).

Foi adotado um diário de campo para registrar os temas que foram objeto de debates, percepções, inquietações dos participantes dos Fóruns de Cidadania, para que este material pudesse ser analisado posteriormente. A análise dos dados coletados teve por objetivo: "compreender criticamente o sentido das falas ocultas" (CHIZZOTTI , 2003, p. 98).

Os sujeitos da pesquisa são pessoas idosas, funcionários da Prefeitura do Município de São Paulo e profissionais da Assistência Social e de outras áreas do conhecimento que acompanham o debate acerca do envelhecimento na cidade.

O presente estudo foi desenvolvido na perspectiva freireana, portanto, a construção do conhecimento foi permeada por diálogos entre as pesquisadoras e os participantes dos Fóruns de Cidadania.

O que se pretende com o diálogo, em qualquer hipótese (seja em torno de um conhecimento científico e técnico, seja de um conhecimento 'experimental'), é a problematização do próprio conhecimento em sua indiscutível reação com a realidade concreta na qual se gera e sobre a qual incide, para melhor compreendê-la,

\section{RESULTADOS E DISCUSSÃO}

O primeiro Fórum de Cidadania foi criado em 1995 e algumas condicionantes contribuíram para o surgimento desses espaços coletivos de participação social e idosos, como se vê a seguir.

Após a promulgação da Constituição Federal de 1988 e o surgimento de leis específicas para os idosos, o debate sobre a temática do envelhecimento ganhou densidade e adentrou por diversos espaços: universidades, ONGs, Conselhos de direitos de idosos, governos, entre outros.

E, aconteceram ganhos nesse processo, entre os quais se destaca a complexidade que tomou a gestão do envelhecimento, exigindo maior aprofundando e o diálogo entre profissionais de várias áreas do conhecimento. (DEBERT, 1994)

As questões dos idosos, especialmente dos menos favorecidos economicamente, deixaram ser tratadas como problema a ser resolvido apenas no âmbito 

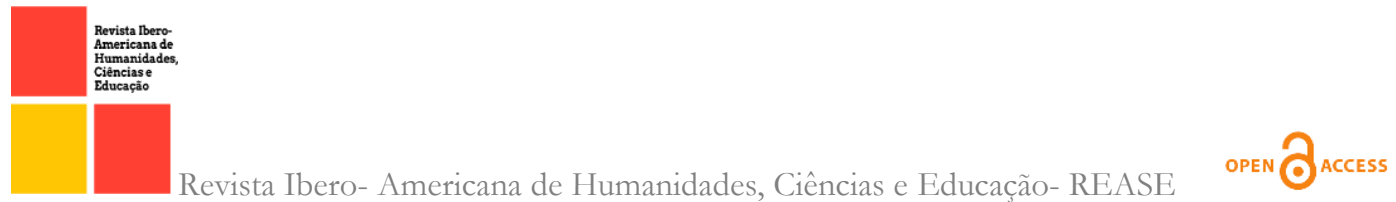

familiar e passaram a ser compreendidas na perspectiva dos direitos da cidadania, ou seja, olhar e enfrentamento semelhantes aos desenvolvidos nos Fóruns de Cidadania.

A constituição de Fóruns de Cidadania significou uma inovação na forma de participação do segmento idoso, uma vez que não havia ocorrido participação social desta natureza na cidade de São Paulo.

O estudo mostrou que o despertar dos idosos sobre a importância da participação social aconteceu no processo, pois, na ocasião em que os Fóruns de Cidadania foram criados, a maioria dos idosos não a valorizava. A seguir relatos de duas pessoas idosas que residem na região leste da cidade de São Paulo e que espelham essa conquista. "Se os idosos não se unirem as leis vão ficar engavetadas, o Estatuto do Idoso, tudo. Por que o governo só funciona na base da pressão. Então, o negócio é ir até a Prefeitura, o negócio ir até lá e fazer pressão" (sr. AJ ). E da sra. CM “Os Fóruns em seus anos de existência cumpriram um papel importante na história da cidade de São Paulo porque debaterem todos os acontecimentos que poderiam afetar de algum modo a vida dos idosos, a nossa vida porque eu sou idosa“.

A pesquisa revelou que a questão central dos Fóruns de Cidadania diz respeito à efetivação de direitos previstos em leis específicas para população idosa. Compete ao Estado, em cada um dos três níveis de governo, garantir a efetivação de direitos, das políticas públicas. Portanto, como diz Gohn “O Estado é sempre elemento referencial definidor, porque é na esfera pública estatal que se asseguram direito, da promulgação à garantia do aceso, e as sanções cabíveis pelo descumprimento dos direitos já normatizados e institucionalizados” ( GOHN, 2013, p.261)

Não resta dúvida: o Estado é responsável pela efetivação de direitos, porém, merece destacar que a participação ativa da sociedade civil na definição e controle de sua execução é fundamental para a consolidação da sua dimensão efetivamente pública" (RAICHELIS E WANDERLEY, 2005, p.5)

O estudo mostrou que circunstâncias no âmbito local contribuíram para criação e ampliação desses espaços de participação social, como aproximação de profissionais de diversas áreas do conhecimento que trabalham junto com a população idosa e profissionais da Prefeitura do Município de São Paulo subsidiando teoricamente os debates 
e orientando no momento de encaminhamentos às autoridades competentes com o propósito de atender de modo satisfatório as demandas trazidas pelos idosos.

Nos Fóruns de Cidadania localizados em regiões periféricas e com histórico de participação social, os debates sobre direitos são mais intensos. A fala de liderança idosa (Sra. MJ) retrata essa questão.

O povo da periferia é muito diferente da classe média que vive lá em Pinheiros. Aqui em São Mateus tem muita gente disposta a fazer, a participar. Também a gente mora num bairro que foi tudo construído em mutirão. A população está acostumada a se reunir. Quando eu digo que preciso de gente para ir em tal lugar para levar um ofício, participar de alguma reunião as próprias idosas se oferecem.

A pesquisa mostrou que a atuação de profissionais tem sido fundamental para ampliação da consciência cidadã das pessoas idosas. A seguir relato de uma profissional da Assistência Social a respeito do que a motiva a prestar assessoria técnica voluntária nos Fóruns de Cidadania: "(...) a consciência de contribuir para que o idoso tenha voz ativa. $\mathrm{Na}$ construção de um novo conceito de envelhecimento, de apropriação de sua cidade, de seu país, resgatando sua história pessoal e coletiva”. (Sra. CR).

O relato da Assistente Social mencionado anteriormente reflete a importância da atuação dos Fóruns de Cidadania no sentido da desconstrução da imagem social sobre a velhice. Pesquisas acadêmicas vêm mostrando ao longo das últimas décadas que preconceitos etários limitam oportunidades dos idosos se inserirem em vários contextos como no mercado de trabalho e não consideram a contribuição econômica e imaterial dos idosos nas suas famílias, na comunidade, na sociedade como um todo, conforme afirma Anita Neri: Muitos preconceitos e estereótipos resultam de falsas crenças a respeito da
competência e da produtividade dos idosos. Seu resultado é a discriminação social por
critério de idade, fundamentalmente motivada por razões econômicas. Como
membros menos capazes e improdutivos da sociedade, os idosos passam a valer
menos nos processos de trocas sociais e, assim, não podem ter acesso à mesma
quantidade de recursos garantidos aos jovens e adultos capazes e produtores dos
bens. (NERI, 2007, p. 37) inúmeros estereótipos que fazem referência aos idosos em geral: o idoso vive reclamando de algo, o idoso está sempre de mau humor, o idoso é muito acomodado, o idoso só fala sobre 
suas doenças, entre outros, quando se sabe que as pessoas são distintas umas das outras. "Eu era uma mulher que dedicava 24 horas do meu dia pra casa, pra cuidar da família. Comecei a participar com 6o anos e não parei mais. Aprendi a nadar, a dirigir, a lutar pelos direitos dos idosos, aprendi a viver com mais liberdade, cuidar melhor de mim " (Sra. EM)

A luta contra a discriminação etária é fundamental num processo de educação para o envelhecimento e sobre o envelhecimento e a velhice, conforme afirma Faleiros (2014). " É preciso romper o silêncio sobre a velhice e abrir espaços na escola, na família, nas pesquisas e na sociedade para se falar abertamente dessa questão" (FALEIROS, 2014, p.13).

O fato é que, os idosos são distintos uns dos outros. E o estudo mostrou que por meio dos Fóruns de Cidadania, os idosos estão se recusando a permanecer nos lugares que lhes foram definidos social e culturalmente. Não estão mais restritos à dimensão privada, o que é fundamental, pois, como diz Arendt: "O homem privado não se dá a conhecer e, portanto, é como se ele não existisse" (ARENDT, 1991, p. 68).

Os idosos vêm redefinindo o seu agir e caminhando na direção de viver de uma forma mais livre, levando em consideração os seus desejos, anseios e na busca da realização do seu eu e não apenas o cumprimento do que dizem as convenções sociais, morais.

Participar, do latim participare, significa tomar parte em algo, pertencer a, mas também significa fazer saber, informar, comunicar. Os participantes dos Fóruns de Cidadania vêm acompanhando as discussões promovidas pela Comissão Extraordinária Permanente dos Idosos da Câmara Municipal de São Paulo composta por Vereadores. Propondo pautas e solicitando acompanhamento de parlamentares de serviços prestados pela Administração Pública Municipal. A atuação dos Fóruns de Cidadania nesse espaço é relevante, pois a participação de idosos no poder legislativo nas esferas federal, estadual e municipal ainda é incipiente no Brasil.

Participação social não se trata de algo estático, é o resultado de um processo em permanente construção, sem fim. A atuação de idosos em Fóruns de Cidadania é compreendida nesta perspectiva porque como bem disse Bobbio " os direitos não nascem todos de uma vez, nem de uma vez por todas” (BOBBIO, 1992. p. 6).

O estudo mostrou que integrantes dos Fóruns de Cidadania, por diversas vezes, têm ocupado a presidência e a vice-presidência do Conselho de direitos das pessoas idosas do Município de São Paulo, Órgão permanente, paritário (com o mesmo número 
de representantes governamentais e não-governamentais) e deliberativo, portanto, contribuído junto com seus pares para formular, acompanhar, fiscalizar e avaliar a Política Municipal dos Direitos da pessoa idosa, zelando pela sua execução.

A pesquisa mostrou que os Fóruns vêm enfrentando desafios na sua trajetória como fragilidades na sua organização, como se observa no relato de um senhor idoso morador da região sul da cidade de São Paulo "É preciso armazenar a documentação dos Fóruns. Os eventos não são fotografados, muita coisa se perdeu nesta caminhada porque quase nada foi registrado”. ( Sr. AML)

A falta de suporte material para realização de atividades foi identificada na pesquisa como desafio. Idosos fazem ligações de seus celulares, utilizam os seus computadores e acessam a internet contratada por eles visando dar encaminhamento às deliberações do grupo.

A constituição do sujeito coletivo Fóruns de Cidadania se dá no processo, nas ações que se repetem e se recriam. A partir do conhecimento dos participantes de leis específicas para o segmento e da defesa de seus direitos.

Para além dos desafios acima mencionados, os resultados mostraram que os Fóruns de Cidadania vêm obtendo ganhos na sua caminhada, como as mudanças que estão sendo incorporadas no âmbito do governo local, no sentido de constituir uma interlocução entre a Prefeitura do Município de São Paulo e o segmento idoso.

\section{CONSIDERAÇÕES FINAIS}

O envelhecimento é um processo individual e complexo, influenciado por diversos fatores que interagem entre si. Os fatores biológicos, psicológicos, sociais, culturais, econômicos, políticos, espirituais e, o modo como o indivíduo vive e se relaciona com o meio, são elementos fundamentais para se compreender esse processo.

A velhice deve ser pensada como um processo dinâmico, em constante mudança. Os Fóruns de Cidadania são espaços privilegiados para desconstrução da imagem social da velhice, compreendida como se fosse um grupo de pessoas não diferenciadas, dotadas dos mesmos atributos e que remetem para representação geral que lhes é comum.

A longevidade é um fenômeno do nosso tempo, da nossa sociedade. Assim sendo, governos, Fóruns de Cidadania, Conselhos de Direitos das Pessoas idosas, 
Universidades, ONGs, profissionais que trabalham junto com os idosos, pesquisadores, cada um de nós, enfim, juntos precisamos encontrar alternativas que promovam a dignidade da pessoa idosa, levando em consideração as múltiplas dimensões do processo do envelhecimento.

Apesar dos obstáculos que os Fóruns de Cidadania vêm enfrentando na sua trajetória como fragilidade de organização, falta de recursos financeiros para realização de suas atividades, estes não superam as conquistas alcançadas no que se refere à ampliação da participação social na dimensão local e do diálogo entre os poderes executivo e legislativo municipal e participantes deste espaço coletivo sobre questões demandadas pela população idosa que reside na cidade de São Paulo.

Acreditamos que a inclusão da temática da longevidade humana, a partir de diálogos entre participantes dos Fóruns de Cidadania e grupos mais fragilizados: mulheres, negros, crianças e adolescentes, entre outros poderá construir caminhos, apontar alternativas na direção da construção de uma sociedade para todas as idades, solidária e fraterna para todos. Como nos ensina Freire "Não há amanhã sem projeto, sem sonho, sem utopia, sem esperança, sem o trabalho de criação e desenvolvimento de possibilidades que viabilizem a sua concretização" (Freire, 2005, p.85).

Por fim, merecer pontuar que as ações empreendidas nos Fóruns de Cidadania visando contribuir para um envelhecer mais saudável e no sentido da construção de uma sociedade solidária, fraterna e para todas as idades são relevantes pois, como afirma Wanderley .

Vivemos numa época que carece de novas utopias, novos experimentos e iniciativas, não apenas sonhos ou desejos românticos afastados da realidade, mas projetos antecipatórios de um novo ideal de convivência, que seja capaz de incluir a subjetividade, individual e coletiva, e que estimule o desenvolvimento da solidariedade (Wanderley,2004, como citado em Luzio dos Santos, 2007, p.57).

\section{REFERÊNCIAS}

ARENDT, H. A condição humana. 5. ed. Rio de Janeiro: Forense, I99I.

BARROSO, Áurea E. Soares. Participação da sociedade civil em políticas públicas voltadas à população idosa. Envelhecimento e Saúde. Boletim do Instituto de Saúde (Impresso), v. 47, p. 33-35, 2009. 
BOBBIO, Norberto. A era dos direitos. Rio de Janeiro: Campus, 1992.

BRASIL. [Constituição (1988)]. Constituição da República Federativa do Brasil. Brasília, DF: Presidência da República, [2021]. Disponível em: http://www.planalto.gov.br/ccivil_03/.htm. Acesso em: is jun. 2021.

BRASIL. Lei no $\mathbf{8 . 8 4 2}$, de 4 de janeiro de 1994. Dispõe sobre a Política Nacional do Idoso, cria o Conselho Nacional do Idoso e dá outras providências. Diário Oficial da União 1994; 4 jan

BRASIL. Lei no. 10.74I, de Io de outubro de 2003. Dispõe sobre o Estatuto do Idoso e dá outras providências. Diário Oficial da União. 03 out. 2003: II. Disponível em: http://www.planalto.gov.br/ccivil_03/leis/2003/Lio.74r.htm »http://www.planalto.go v.br/ccivil_03/leis/tm. Acesso em: I5 de junho de 202I.

BRASIL. Portaria n. 2.528, de 19 de outubro de 2006. Aprova a Política Nacional de Saúde da Pessoa Idosa e determina outras providências. Diário Oficial da União 2006; 19 out

CARletto, A. C. Prefeitura do Município de São Paulo. Secretaria Municipal de Direitos Humanos e Cidadania. Indicadores Sociodemográficos da população idosa residente na cidade de São Paulo. 2020

CHIZZOTTI, Antônio. Pesquisa em Ciências Humanas e Sociais. 6. ed. São Paulo: Cortez, 2003.

DALLARI, Dalmo de Abreu. Um breve histórico dos direitos humanos. In: CARVALHO, José Sérgio. Educação, cidadania e direitos humanos. Petrópolis, RJ: Vozes, 2004

DEBERT GG (org). Antropologia e velhice: textos didáticos. Campinas: IPCH/Unicam, 1994

DIESE - Departamento Intersindical de Estatística e Estudos Socioeconômicos. Boletim Especial $\mathrm{n}^{\circ}$ or - Quem são os idosos brasileiros https://www.dieese.org.br/boletimespecial/2020/boletimEspecialor.html Acesso em o9 set 202I

DÓREA, Egídio. Revolução da Longevidade. RIOTO, Inês Andrade; BARROSO, Áurea Soares; VIANA, Edgard Borsoi. (Orgs). Morar 6o Mais. Revolucionando a moradia em face da longevidade. A4 Editora, 2021

FALEIROS, V. P. Envelhecimento no Brasil do Século XXI: transições e desafios. Argumentum (Vitória), v. 6, p. 6-21, 2014.

FREIRE, P. Pedagogia do oprimido 4I.ed. Rio de Janeiro; São Paulo: Paz e Terra, 2005

FREIRE, Paulo. Extensão ou Comunicação? 17. ed. São Paulo: Paz e Terra, 2015. 
GOHN, M. G. M. . Desafios dos movimentos sociais hoje no Brasil. Ser Social (UnB), v. I5, p. 301-311, 2013.

IBGE - INSTITUTO BRASILEIRO DE GEOGRAFIA E ESTATÍSTICA. Projeções da população: Brasil e unidades da federação. In: IBGE. Coordenação de população e indicadores sociais. 2.ed. Rio de Janeiro: IBGE, 2018. Revisão 2018.

MARTINELli, M. L. Pesquisa qualitativa: um instigante desafio. 2. ed. São Paulo: Veras Editora, v. I. 2012

NERI, A. L. (Org). Idosos no Brasil: vivências, desafios e expectativas na terceira idade. São Paulo: Editora Fundação Perseu Abramo, Edições SESC, SP, 2007

OMS - ORGANIZAÇÃO MUNDIAL DA SAÚDE. Relatório Mundial de Envelhecimento e Saúde (2015) https://sbgg.org.br//wp-content/uploads/2015/ro/OMS ENVELHECIMENTO-2015-port.pdf Acesso em 15/08/2021

Prefeitura do Município de São Paulo. Secretaria de Direitos Humanos e Cidadania. Indicadores Sociodemográficos da população idosa residente na cidade de São Paulo. 2020

RAMOS, L. R. Saúde Pública e envelhecimento: o paradigma da capacidade funcional.BIS. Boletim do Instituto de Saúde (Impresso), v. 47, p. 40-42, 2009.

ROSA,Tereza Etsuko da Costa; BARROSO,Áurea Eleotério Soares;LOUVISON,Marília Cristina Prado. Prado. Velhices: experiências nas políticas do envelhecimento ativo. São Paulo: Instituto de Saúde, 2013

SANTOS, Luís Miguel Luzio dos. Organizações da sociedade civil: entre a solidariedade libertária e a liberal. 2007. 249 f. Tese (Doutorado em Ciências Sociais) - Pontifícia Universidade Católica de São Paulo, São Paulo, 2007.

TÓTORA, Silvana. A vida nas dobras... as dobras da velhice. In. A Terceira Idade SESCSP. v.19, no. 43, p. 27-38. São Paulo, outubro de 2008.

VIEIRA, Evaldo Amaro. Os direitos e a política social. São Paulo: Cortez, 2. ed. 2007.

UNFPA, Fundo de População das Nações Unidas. Resumo Executivo Envelhecimento no Século XXI: Celebração e Desafio. Disponível em: 〈https://www.unfpa.org/sites/default/files/pub-pdf/-Summary_o.pdf〉. Acesso em: i7 jul. 2021. 